\title{
The Growth and Impact of OTT on Video Viewing Behavior
}

\author{
Joon-Ho Lee1)
}

\begin{abstract}
This study investigates the current and future growth trends of OTT(Over-the-Top) services and the changes in the pattern and type of viewing behavior among audio-visual media users. This is followed by analyses of the background and concerns behind these trends. The investigation was conducted after a careful review of related literature and gathering secondary up-to-date statistical data. The result of this research was that three implications and concerns about the growing competition became evident. First, the entrance and localization of global OTTs in the Korean market may have a positive effect on investment in terms of content production and staff employment, while simultaneously having a negative effect through the monopolization of video distribution networks. Second, the changes in the video market will cause media regulation authorities to enact a new visual media law with the objective of rearranging of the competing market. This will start with redefining the term and entire concept of 'broadcasting'. Third, Korean OTT users tend not to be cord-cutters, however, they would become more selective if competing OTT services provide continually attractive subscription fees, content to binge-watching, and high service quality.
\end{abstract}

Keywords : OTT, Broadcasting, Cord-cutter, Binge-watching, Localization

\section{Introduction - Intent of the Study}

There is almost nothing that is immune to the revolutionary change the Internet has caused since 1990s. The usage and application of the Internet have transformed almost every aspect of the way human society lives and works. One of the most remarkable changes of this revolution is in the field of visual mass communication media particularly in terms of broadcasting and movie. Traditional television media transmissions such as terrestrial, cable, and satellite networks are moving towards online, digitalized, smart, and mobile forms of media and these forms require devices that correspond to the new network and these in tern are radically changing the media usage modes worldwide.

This trend is being led by large content and platform corporations throughout the United States. These corporations are rapidly growing and this can be seen in their increased use of various marketing methods, co-ops, and M\&As, and in their ever expanding influence and

Received(September 12, 2019), Review Result(1st: October 10, 2019, 2nd: November 15, 2019), Accepted(December 23, 2019)

1) (Professor) 47340 Department of Communication \& Media, Dong-eui Univ., Eomgwangno 176, Busanjin-gu, Busan, Korea

e-mail: joonlee@deu.ac.kr 
dominance in the world media markets. The preexisting tendency of the majority of viewers to watch real-time broadcasting and pay TV platforms has been superceded by VOD (Video-on-Demand) and user participation-centered video services which simplify or delete the functions of platform transmission and these services have now penetrated deeply into the life of most visual media users. The representative example is OTT (Over-the-Top) services such as Netflix and Hulu, and UCC (User Created Content) services such as Youtube. OTT is a streaming media service offered directly to viewers over the Internet. It bypasses cable, broadcast and satellite television platforms that have traditionally acted as a controller or distributor of such content[1]. UCC, alternatively known as user generated content (UGC), is any form of content, such as images, videos, text and audio, that has been posted by users on online platforms such as social media and wikis[2]. As mentioned, both OTT and UCC platforms do not need a specially designed ancillary device such as a set-top box to show viewable video signals to subscribers only, and are commonly called "OTT" services. Instead, they provide variable videos and content following a log-in process or for free. OTT services can be used with any digital devices connected to the Internet as well as television sets.

As of 2019, over a half of all American households subscribe to Netflix OTT services, and there are nearly 100 million paying subscribers outside the US. Youtube is another popular alternative form of media replacing traditional TV viewing, and this internet site provides primarily free UCC content to a majority of the worldwide population with Internet access. Their revenue and net profits have been growing simultaneously with the growth of user base. In the case of Korea, the number of Netflix subscribers is now approaching 2 million with 70\% of the population being regular viewers of Youtube content[3].

In the first part of this study, the rise and growth of OTT services to now occupy and share a significant portion of the visual media market will be described and analyzed, followed by a description of the reasons and background behind this trend. Secondly, significant changes in viewing behaviors and patterns of visual media users after the introduction of OTT to Korea will be analyzed. Third and finally, important emerging prospects and concerns of the newly emerging media phenomena will also be suggested and discussed. In order to achieve these objectives, related literature and secondary relevant up-to-date data have been collected, reviewed, and synthesized purposively.

\section{The Rise and Expansion of OTT Media}

OTT began along with a new trend in the 1990s in which Internet-based, interactive visual 
media started to serve alternative platforms and content to traditional broadcasting, packaged visual media, and subscription TV. The first launcher of this service was Netflix, a former mail order video rental company, that moved its video services onto the Web in 1998. As of 2019, Netflix has established 150 million paid subscriptions worldwide in 190 countries with 5 million subscriptions using their free trial promotion system[4].

[Table 1] shows the rapid growth of Netflix's business over the last 13 years[5]. Its revenue, net profit, stock price, and number of employees have all dramatically increased by an average of 2-digit percentage points yearly. Among them, its profitability and price per share have grown fastest expanding $85.7 \%$ and $58.2 \%$ per year, respectively.

[Table 1] Yearly Financial Data of Netflix

\begin{tabular}{|c|r|r|r|r|}
\hline Year & Revenue (mil. \$) & Net income (mil.\$) & Price per Share (\$) & Employees \\
\hline 2005 & 682 & 42 & 2.59 & \\
\hline 2006 & 997 & 49 & 3.69 & \\
\hline 2007 & 1,205 & 67 & 3.12 & \\
\hline 2008 & 1,365 & 83 & 4.09 & \\
\hline 2009 & 1,670 & 116 & 6.32 & \\
\hline 2010 & 2,163 & 161 & 16.82 & 2,180 \\
\hline 2011 & 3,205 & 226 & 27.49 & 2,348 \\
\hline 2012 & 3,609 & 17 & 11.86 & 2,045 \\
\hline 2013 & 4,375 & 112 & 35.27 & 2,022 \\
\hline 2014 & 5,505 & 267 & 57.49 & 2,450 \\
\hline 2015 & 6,780 & 123 & 91.90 & 3,700 \\
\hline 2016 & 8,831 & 187 & 102.03 & 4,700 \\
\hline 2017 & 11,693 & 559 & 165.37 & 5,500 \\
\hline 2018 & 15,794 & 1,211 & 293.35 & 7,100 \\
\hline Avg. Growth Rate & $27.8 \%$ & $85.7 \%$ & $58.2 \%$ & $17.4 \%$ \\
\hline
\end{tabular}

Netflix started to spend increasing amount of its operating budgets on its streaming video services in 2008 after establishing production partnership with major Hollywood studios in 2010, and they also increased investment in their original programs production of drama series and movies such as 'House of Cards' and self-produced movies. This was coupled with a more considered localization of content with well-targeted content for each different country being produced since 2012. In 2018, Netflix spent over 10 billion dollars on its original content production throughout the world market. Netflix's differentiated and expanding marketing strategies include, first, avoidance to joining or cooperating with predominant market players, securing a much higher proportion of profit share than its partners when signing partnership 
contracts. These are the main factors that enabled the consistent success of Netflix's business.

Besides Netflix, The Walt Disney Company, a main competitor and partner of Netflix which has abundant original content that appeals to world OTT users, will launch their own streaming service named 'Disney Plus' in late 2019. As a result, Disney content currently hosted on Netflix will begin to be phased out over the next couple of years. Apple is also preparing itself to enter the market with its own type of specialized content such as magazines and music. WarnerMedia is about to launch a service with the release of its own specialized content of movies and dramas after the acquisition by AT\&T in 2018. In addition, Youtube and Amazon have each begun to provide new premium services. Although the competition among global OTT platforms are becoming intense, each player in the global industry is expected to gain increased revenue and profit because the total pie of the OTT market is growing at the same pace and the content and services provided by the players are becoming more and more differentiated and specialized[6].

Another monopolistic OTT giant is Youtube which was founded in 2005 by three former employees of PayPal in order to build an easily accessible website for video clip sharing. Youtube has grown exponentially through the world because of its free video services, because it has facilitated personal UCCs that can generate advertising income in accordance with the viewer size, and because of interactivity with other forms of social media. Youtube serves 102 different countries with localized IP and language for each location. Now a YouTube Premium (formerly YouTube Red) subscription service offers advertising-free streaming access to exclusive content as well as real-time broadcasting services.

As most digitally advanced countries' broadcasting and video service markets have become heavily saturated by diverse players who provide similar programs and content using different platforms and networks, the competitiveness of OTT services, especially mobile services, are more likely to be superior to preexisting media and platforms and this is the case in both complementary and substitutionary senses[7].

The [Fig. 1] and 2 show the tendencies and forecasts for the number of worldwide subscriptions to OTT services from 2014 through 2022[8].

[Fig. 1] clearly demonstrates the rapid growth of OTT subscriptions compared to pay-TV (cable, satellite, and IPTV). It is forecast that the number of OTT subscribers will exceed pay-TV subscribers after 2022.

[Fig. 2] compares global OTT subscriptions for two companies and by two types of services. Both Netflix and Amazon have expanded and are expected to grow sustainably in the global video market for the time being with a 50 million difference. Also, SLIN (Subscription-based 
Linear) OTT services, such as Youtube that can provide real-time videos, are expected to grow slightly faster than VOD-based subscription services.

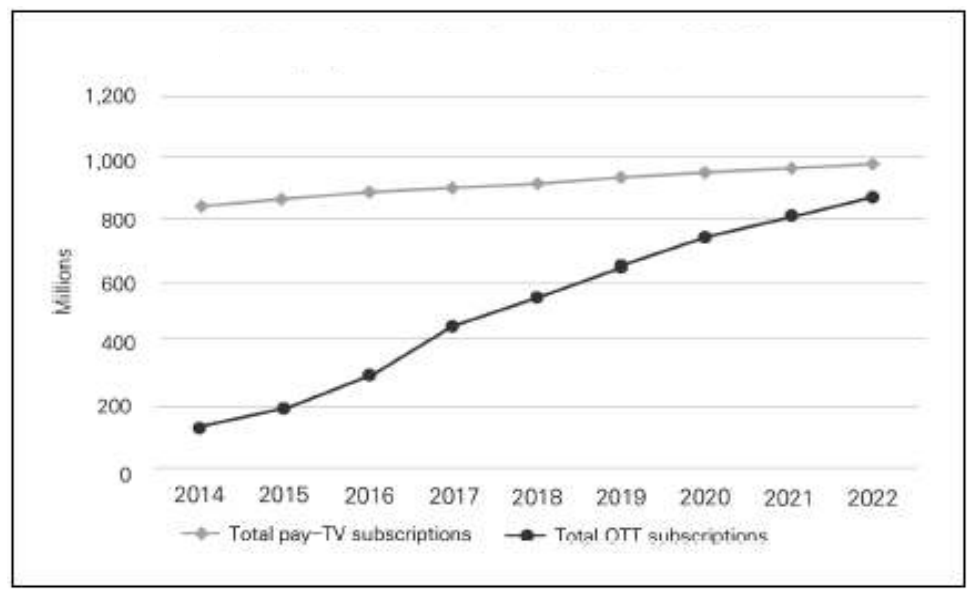

[Fig. 1] Subscriptions to Global Pay-TV and OTT (unit: millions)

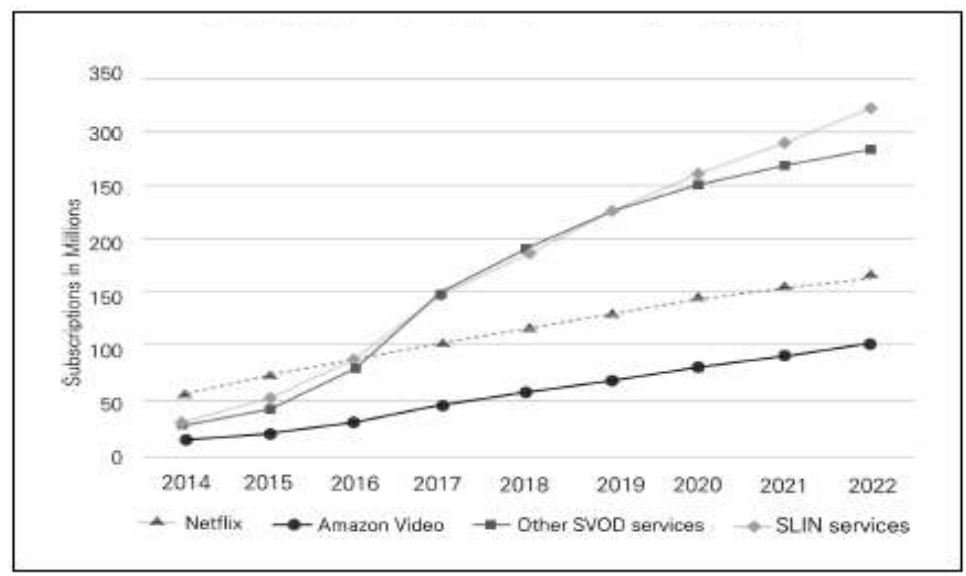

[Fig. 2] Global OTT Subscriptions by Company and Type (unit: millions)

\section{The Changes in Video Viewing Behavior}

In terms of viewing behavior of visual and broadcast content, there has been a big shift from realtime television viewing to VOD (Video-on-Demand) and binge watching content, and there are big differences in viewing styles between preexisting TV media and the current forms of OTT. OTT services can be conveniently used with a variety of mobile smart media and provide a multitude of viewing functions, such as auto forward for binge-watching, 
resume-watching, skip-watching. They also provide a variety of viewing packages with different price tiers. This si especially true for global OTT platforms that are secure and they spend huge amount of their budget on producing their original high quality programs and content. They also localize content that is suited to and aimed at the different tastes of users in each different country. For these reasons, the number of world subscribers to OTT services has grown at an average annual rate of $50 \%$ for the last several years, and now includes almost $10 \%$ of total global population.

In the case of Korea, real competition among various OTTs has been ongoing since Netflix entered the market with a partnership with LG U+ in 2016. The total number of users for the three representative foreign OTT services (Youtube, Netflix, TikTok) is about 30 million with an increase of $15.5 \%$ in the last year from July 2018 to July 2019. Meanwhile, the number of domestic OTT subscribers dropped by $10.4 \%$ throughout the same period. The exceptions to this trend were the cases of Pooq and Oksusu. Pooq, an OTT platform founded by a consortium of three Korean terrestrial broadcasters, and Oksusu, owned by SK Telecom, signed a merger contract into a new domestic OTT, Wavve. This was accomplished with the assistance of Korean Communications Commission (KCC) in order to compete with present and future foreign OTTs, such as Netflix, Disney, and AT\&T[9][10]. The synergy effect from the merger case has not yet been calculated.

[Table 2] Yearly Subscription Data of OTTs in Korea

\begin{tabular}{|c|c|c|c|c|}
\hline \multirow{2}{*}{$\begin{array}{l}\text { Major OTTs in } \\
\text { Korea }\end{array}$} & \multicolumn{2}{|c|}{ Fiscal Year } & \multirow{2}{*}{ Increase } & \multirow{2}{*}{$\begin{array}{l}\text { Growth } \\
\text { Rate }\end{array}$} \\
\hline & July 2018 & July 2019 & & \\
\hline Netflix & 419,667 & $1,855,334$ & $1,435,667$ & $342.1 \%$ \\
\hline Youtube & $24,660,691$ & $26,316,131$ & $1,665,440$ & $6.7 \%$ \\
\hline TikTok & 870,693 & $1,805,749$ & 935,056 & $107.4 \%$ \\
\hline Foreign Total & $25,951,051$ & $29,977,214$ & $4,026,163$ & $15.5 \%$ \\
\hline Oksusu & $3,137,698$ & $3,361,973$ & 224,275 & $7.1 \%$ \\
\hline Pooq & 761,176 & $1,396,462$ & 635,286 & $83.5 \%$ \\
\hline Naver TV & $3,233,588$ & $1,938,876$ & $-1,294,712$ & $-40.0 \%$ \\
\hline U+ Mobile TV & $2,359,173$ & $1,790,777$ & $-568,396$ & $-24.1 \%$ \\
\hline Olle TV Mobile & $1,464,680$ & $1,329,704$ & $-134,976$ & $-9.2 \%$ \\
\hline Afreeca TV & $1,477,328$ & $1,224,484$ & $-252,844$ & $-17.1 \%$ \\
\hline MX Player & $1,785,409$ & $1,696,925$ & $-88,484$ & $-5.0 \%$ \\
\hline Domestic Total & $14,219,052$ & $12,739,201$ & $-1,479,851$ & $-10.4 \%$ \\
\hline
\end{tabular}

According to '2018 Annual Research of Usage Patterns among Broadcasting Media' conducted and published by KCC, $42.7 \%$ of Koreans used OTT services throughout 2018. Those who use 
OTT on an almost daily basis total $15.4 \%$ and those who use it 4 times or less per week amount to $22.5 \%$. The usage rate has increased from $35.0 \%$ in 2016 to $36.1 \%$ in 2017 . The most preferred content type is entertainment (67.4\%), followed by drama (32.6\%), sports (25.9\%), news reports $(22.5 \%)$, and current affairs programming $(11.4 \%)$. Females tend to view more entertainment, dramas, and current affairs whereas males view more sports and news. The OTT use rate varies depending on the users' age. Viewers in their 20 s are most loyal to OTT services $(78.4 \%)$, and those in their teens are second $(71.7 \%)$, followed by the $30 \mathrm{~s}(64.2 \%), 40 \mathrm{~s}$ $(44.6 \%), 50 \mathrm{~s}(23.0 \%)$, and $60 \mathrm{~s}$ and the older $(6.9 \%)$. The results show that younger the viewers, the higher their use rate of OTT. However, the usage rate is steadily increasing across the age groups. Almost all the viewers (93.7\%) view OTT content using smartphones, and the second and third devices are desktop PCs (8.2\%) and laptops (5.2\%). Less than 5\% of viewers use tablet PCs $(4.4 \%)$ and TV sets $(2.4 \%)$. It follows then that most of these viewers enjoy watching OTT content by using a free wi-fi connection. Korean OTT users tend to view short edited content of 5 minutes or less $(56.7 \%)$ and non-broadcast or OTT-exclusive content $(67.3 \%)$ by themselves $(31.6 \%)[11]$.

Korean OTT users tend to choose their services based on preference first according to cost, then content, then service quality, and finally the convenience of use in that order. They seek OTT services of relatively lower cost first then consider the amount of domestic content, the video quality and finally the stability of services. In terms of competition among services as it relates to the preferences of users, the domestic OTT services, Pooq, Tving, and Oksusu strongly compete against each other. However the international OTT, Netflix, is currently superior to these other services in most aspects except the amount of content[12]. Another Empirical study proved that Korean Netflix users were more likely to be satisfied and to continuously use it if the service provides more imported and original content and more diverse rate tiers[13].

\section{Industrial and Behavioral Implications and Concerns}

The global trend whereby video consumption behavior increasingly depends on Internet-based video service platforms is forcing the Korean visual media industry to become more competitive and complex. As additional global video players such as Disney Plus, Apple TV Plus, and Youtube Premium continue to enter the competition in the late part of 2019 and afterwards, the market structure will face rapid change in terms of preexisting marketing strategies, M\&As, and partnerships. These changes in the industry will lead to many 
implications and challenges concerning future competition, policy, and user behavior and are as follows:

(1) The entrance and development of global OTTs pioneered by Netflix in the Korean video market have had great impacts on content production and transaction. The increasing localization of Netflix, Youtube, and the other OTTs, including massive purchases and co-production of Korean programs, has had positive effects on Korean creators, producers, and content providers in terms of securing global distribution, improving negotiation power, and enhancing the production environment in general, but has also led to negative effects such as the monopolization of the domestic distribution network by Netflix and other global OTTs[14].

(2) There have been much debate and study on how best to introduce a new regulation system or an amendment to existing broadcasting and visual media law. The present regulatory consideration is called 'asymmetric regulation' in which prior and dominant participants in the market are severely regulated while new and non-dominant counterparts are less regulated. In this respect, OTT services are not considered within the boundary of broadcasting and are free from governmental regulation. This approach has been criticized by a number of mass media researchers as well as terrestrial broadcasters[15]. In the constitutional sense, OTTs could be considered a broadcasting service if they generally contribute to the free formation of public opinion and could be almost equally regulated under the notion that broadcasting, pay TV, and OTTs are almost the same service. However, the noticeable variety and differences OTT services provide compared to prior broadcasting could function as non-broadcasting services, and have tended to make legislators hesitant to introduce a new regulating system. Therefore, in the negotiating and moderating sense, the EU (European Union) countries have set a regulative standard that is applicable to OTTs as AVMS (Audio-Video Media Services), and many Korean scholars support a step-by-step gradual incorporation of OTTs into the legal definition or the range of broadcasting in the process of enacting of new broadcasting laws[16].

(3) In terms of the change in visual media using behavior, it has been reported that a significant portion of the U.S. households have switched TV services from pay TV (cable, satellite, IPTV) subscriptions to OTTs, and that the number of OTT subscribers has begun to exceed that of cable TV subscribers as of 2017[17]. This phenomenon is called 'cord-cutting' and is expected to spread worldwide. It is mainly because of the high subscription fees of pay TV in the U.S. and the high quality content of OTTs, especially those of Netflix. It also comes from the change in video usage patterns with TV viewers tending to watch videos of a series, ie., a whole season of drama episodes, purposively and consecutively (binge-watching). In comparison, Korean TV viewers tend to view real-time TV by a rate of $37.8 \%$, habitually watch 
by a rate of $35.4 \%$, instead of using VOD services by a rate of $9.0 \%$, and drama binge watch at a rate of $12.2 \%[18]$. They also tend to show 'cord-stacking' instead of 'cord-cutting' because the monthly rate for pay TV services is not expensive and because every domestic TV platform in Korea severely competes aggressively within a saturated broadcast market, and has designed effective bundle packages for telecommunication (mobile + Internet $+\mathrm{TV}+\mathrm{VoIP}+\mathrm{IoT}$ ) subscriptions.

\section{Conclusion}

The current video service environment in which OTTs and the other video providers, policymakers, and users face significant changes that require an insight that clearly predicts the future competition among video platforms or services as well as media using behavior. The following are main findings and implications of this study that need to be considered.

First. as global OTTs enter the Korean market and use various marketing strategies such as localization and pricing strategies, the immediate responses of domestic counterparts should include the development of M\&A and governmental policy support for the encouragement of cultural industries in order to block the dominating power of the global OTTs. However, it has not yet proved to be effective or prolonged. Secondly, the Korean government as well as other governments face a risk of monopolization within the network video market, and are likely to rearrange their media policy by including OTT services within the category of broadcasting media. This means that legal responsibility of OTTs may become greater in the near future. Finally, Korean OTT users tend not to be cord-cutters but to be cord-stackers, however, they would become gradually more selective if participating OTTs provide more localized attractive services such as providing competitive subscription fees, more binge-watchable content, and better service quality in general.

The current research remains incomplete until subsequent relevant studies clearly explore the relationships between the further growth of more diverse OTTs in the Korean audio-visual media market and the viewing patterns of viewers. It suggests more specific empirical analyses of viewers' OTT using behaviors in the rapidly changing media market.

\section{References}

[1] N. Jarvey, Can CBS Change the Streaming Game With Star Trek: Discovery?, The Hollywood Reporter, (2017) 
[2] P. Berthon, L. Pitt, J. Kietzmann, Jan and I. P. McCarthy, CGIP: Managing Consumer-Generated Intellectual Property, California Management Review, (2015), Vol.57, No.4, pp.43-62, DOI: DOI:10.1525/cmr.2015.57.4.43

[3] https://www.yna.co.kr/view/, Sep 8 (2019)

[4] https://en.wikipedia.org/wiki/, Sep 15 (2019)

[5] https://fortune.com/fortune500/netflix/, Sep 8 (2019)

[6] https://en.wikipedia.org/wiki/, Sep 8 (2019)

[7] J. H. Lee, The Crisis Facing Terrestrial Broadcasters and Reorganization Policy of Television Industry, Asia-pacific Journal of Convergent Research Interchange (APJCRI), (2019), Vol.5, No.3, pp.31-40, DOI : 10.21742/apjcri.2019.09.04

[8] The Road to 2022: Key Consumer and Entertainment Trends, OVUM, (2018)

[9] https://www.yna.co.kr/view/, Sep 8 (2019)

[10] S. Lee, The Changes and Forecasts of Competition among the U.S. OTT Players, KCA Media Issue \& Trend, (2019), Vol.2, No.1, pp.38-52.

[11] Korean Communications Commission, Annual Research of Broadcast Media Usage Patterns, (2018)

[12] E. Kwak and J. Choi, An Analysis of Users' Perception Regarding Service Attributes and Competitive Relationship among OTT Services in the Korean Market, Broadcasting \& Communication, (2019), Vol.20, No.2, pp.121-169, DOI: http://dx.doi.org/10.22876/bnc.2019.20.2.004

[13] J. Yoo and J. Park, A Study on the Factors Influencing Continuous Usage Intension based on OTT Service User, Korean Journal of Broadcasting \& Telecommunications Research (KJBTR), (2018), No.102, pp.46-79.

[14] Y. Hwang, KISDI Premium Report: The Effect of the Entrance of Global OTT Businesses into Korean Market on Media Ecosystem, Korea Information Society Development Institute, (2018)

[15] J. H. Lee, Reconsidering Asymmetric Regulation of Korean Television Industry, Asia-pacific Journal of Convergent Research Interchange (APJCRI), (2018), Vol.4, No.3, pp.53-60.

[16] H. D. Kwon, Constitutional concept of broadcasting and the Justification of Broadcasting Law Regulations for OTT Services, Journal of Media Law, Ethics and Policy (JML), (2019), Vol.18, No.1, pp.1-36, DOI : 10.26542/JML.2019.4.18.1.1

[17] Statista, Netflix Surpasses Major Cable Providers in the U.S., Jun 3 (2017)

[18] Korean Communications Commission, Annual Research of Broadcast Media Usage Patterns, (2018) 